\title{
Effect of Heat Treatment on the Microstructure and Mechanical Properties of the Modified 718 Alloy
}

\author{
Da-Wei Han ${ }^{1} \cdot$ Lian-Xu Yu ${ }^{2}$ Fang Liu ${ }^{3} \cdot$ Bin Zhang ${ }^{1} \cdot$ Wen-Ru Sun ${ }^{3}$ \\ Received: 9 March 2018/Revised: 11 May 2018/Published online: 17 August 2018 \\ (C) The Chinese Society for Metals and Springer-Verlag GmbH Germany, part of Springer Nature 2018
}

\begin{abstract}
M718 alloy with an extra high Mo content of $7.50 \mathrm{wt} \%$ which reduced $\mathrm{Nb}$ addition and increased $\mathrm{Al}$ and Ti additions within the composition specifications of 718 alloy has been designed to increase the service temperature of 718 alloy. And the effect of the heat treatment on the microstructure and mechanical properties of M718 alloy has been investigated in this study. The results showed that Laves phase precipitated on the grain boundaries of M718 alloy instead of $\delta-\mathrm{Ni}_{3} \mathrm{Nb}$ phase in 718 alloy, and $\gamma^{\prime \prime}$ and $\gamma^{\prime}$ phases precipitated in the matrix of M718 alloy as that in 718 alloy. Increasing the solution temperature from 960 to $1050{ }^{\circ} \mathrm{C}$ noticeably reduced the intergranular precipitation of Laves phase. The precipitation of Laves phase was appropriate at $1020^{\circ} \mathrm{C}$ for improving the grain boundary cohesion. Increasing the two-stage aging temperatures markedly increased the sizes of $\gamma^{\prime \prime}$ and $\gamma^{\prime}$ phases. As a result, the strength of M718 alloy increased.
\end{abstract}

Keywords Heat treatment $\cdot$ Mo $\cdot 718$ alloy $\cdot$ Microstructure $\cdot$ Mechanical properties

\section{Introduction}

718 alloy is a precipitation-hardened $\mathrm{Ni}-\mathrm{Fe}$ base superalloy, which is strengthened mainly by $\gamma^{\prime \prime}-\mathrm{Ni}_{3} \mathrm{Nb}$ phase which has the $\mathrm{DO}_{22}$ structure and partially by $\gamma^{\prime}-\mathrm{Ni}_{3}(\mathrm{Al}$, Ti) phase which has the $\mathrm{L}_{2}$ structure [1-3]. Due to its excellent comprehensive mechanical properties, oxidation and hot corrosion resistance, good processability and weldability, 718 alloy has been widely applied in aerospace, nuclear power and oil industries [4-6]. However, the long-term service temperature of 718 alloy cannot be higher than $650{ }^{\circ} \mathrm{C}$, because $\gamma^{\prime \prime}$ phase will be instable and then transform into $\delta$ phase, and thus lose the strength markedly $[7,8]$.

Available online at http://link.springer.com/journal/40195

Wen-Ru Sun

wrsun@imr.ac.cn

1 School of Materials Science and Engineering, Northeastern University, Shenyang 110819, China

2 Chongqing Skyrizon Aero-engine Co. Ltd, Chongqing 401135, China

3 Institute of Metal Research, Chinese Academy of Sciences, Shenyang 110016, China
In the past 30 years, many researchers have carried out a lot of work to improve the microstructure stability of 718 alloy and intended to develop a new 718 type alloy used beyond $650{ }^{\circ} \mathrm{C}$ [9]. One of the methods is to control the precipitation behavior of $\gamma^{\prime \prime}$ phase and $\gamma^{\prime}$ phase by means of modifying $\mathrm{Al}$, $\mathrm{Ti}$ and $\mathrm{Nb}$ contents, and the precipitates with a sandwich structure of $\gamma^{\prime \prime}$ phase and $\gamma^{\prime}$ phase can be obtained by appropriate heat treatment and hence the mechanical properties beyond $650{ }^{\circ} \mathrm{C}$ can be improved. Additionally, the proper addition of $\mathrm{P}$ and $\mathrm{B}$ can lead to a significant improvement in stress rupture life [10-14]. Some researchers have strengthened the alloy matrix by adding solid solution elements. As an important solid solution element, Mo would reduce the bulk diffusion rate and retard the coarsening of $\gamma^{\prime \prime}$ phase and $\gamma^{\prime}$ phase of 718 alloy $[15,16]$, and the increase in Mo content could have a significant effect on the creep rate [17-20].

The present paper concentrates on the effect of the heat treatment on the microstructure and mechanical properties of the modified 718 alloy. For comparison, a commercial 718 alloy treated by the standard heat treatment was also tested. 


\section{Experimental}

In order to improve the service temperature of 718 alloy, a modified 718 alloy (namely M718) was designed by additions of $0.70 \mathrm{wt} \% \mathrm{Al}, 1.10 \mathrm{wt} \% \mathrm{Ti}, 4.80 \mathrm{wt} \% \mathrm{Nb}$ and $7.50 \mathrm{wt} \%$ Mo. M718 alloy and commercial 718 alloy were smelted by vacuum induction melting in this study, and their chemical compositions are listed in Table 1. The tested alloys were homogenized and subsequently forged into bars with $30 \mathrm{~mm}$ in square section, finally hot-rolled into round bars of $18 \mathrm{~mm}$ diameter.

As listed in Table 2, M718 alloy was subjected to four heat treatments as HT1 to HT4, while 718 alloy was only treated by the standard heat treatment HT1. Then, the tensile properties at room temperature and $680{ }^{\circ} \mathrm{C}$ and the stress rupture properties at $680{ }^{\circ} \mathrm{C}$ and $725 \mathrm{MPa}$ were measured.

After grinded and polished mechanically, the samples for microstructure analysis were etched for $75 \mathrm{~s}$ in a solution of $5 \mathrm{~g} \mathrm{CuCl}_{2}, 100 \mathrm{~mL} \mathrm{HCl}$ and $100 \mathrm{~mL} \mathrm{C}_{2} \mathrm{H}_{5} \mathrm{OH}$. The microstructural evolution and precipitation of the phases were carefully characterized by optical microscopy $(\mathrm{OM})$, field emission gun scanning electron microscopy (SEM, JEOL 6340) and transmission electron microscopy (TEM). Energy-dispersive spectroscopy (EDS) was employed to identify the composition of the phases. The TEM specimens were prepared by mechanically grinding to $50 \mu \mathrm{m}$ thick and then twin-jet electropolishing in a solution of $90 \% \mathrm{C}_{2} \mathrm{H}_{5} \mathrm{OH}$ and $10 \% \mathrm{HClO}_{4}$ at $-20{ }^{\circ} \mathrm{C}$ under $20 \mathrm{~V}$.

\section{Results}

\subsection{Microstructures}

As shown in Fig. 1, the microstructures of M718 alloy and 718 alloy were all homogeneous after different heat treatments. The grain size of M718 alloy was about $11 \mu \mathrm{m}$ (as shown in Fig. 1a-c), and that of 718 alloy was about $4.5 \mu \mathrm{m}$ (as shown in Fig. 1d). The white particles with a diameter of approximately $1 \mu \mathrm{m}$ uniformly precipitated on the grain boundaries in M718 alloy, as presented in Fig. $2 \mathrm{a}-\mathrm{c}$. The number of the particles on the grain boundaries decreased noticeably when the solution temperature increased from 960 to $1020{ }^{\circ} \mathrm{C}$, and reduced slightly when the solution temperature increased from 1020 to $1050{ }^{\circ} \mathrm{C}$. When 718 alloy was subjected to HT1, as shown in Fig. 2d, a large number of rod-like $\delta$ phases precipitated on the grain boundaries.

Using the SEM/EDS microanalysis, it was found that the white particles on the grain boundaries of M718 alloy were rich in Mo and Nb, as presented in Fig. 3. It was identified to be Laves phases by selected area electron diffraction (SAED), as shown in Fig. 4. However, no $\delta$ phases were observed in M718 alloy. Collier et al. [21] found that the driving force for the formation of $\delta$ phases decreased with increasing $(\mathrm{Al}+\mathrm{Ti})$ content and reducing the $\mathrm{Nb}$ content in 718 alloy. The lower content of $\mathrm{Nb}$ and the addition of Mo in M718 alloy resulted in the precipitation of Laves phase which in turn consumed a large number of $\mathrm{Nb}$. Therefore, $\delta$ phases did not precipitate on the grain boundaries. In addition, Mo was believed to segregate to the grain boundaries in superalloys [22-28]. Thus, the concentration of Mo at the grain boundaries of M718 alloy was higher than that of 718 alloy. During the nucleation and growth of $\delta$ phase, Mo was expelled out of $\delta$ phase and excessive Mo was gathered at the grain boundaries, which in turn inhibited the precipitation of $\delta$ phase.

The morphologies of the strengthening phases are shown in Fig. 5a-c, and the SAED pattern from the [0 $\left.\begin{array}{lll}0 & 0 & 1\end{array}\right]$ matrix zone axis of M718 alloy is shown in Fig. 5d. The $<001>$ and $<011>$ type superlattice reflections are from both $\gamma^{\prime \prime}$ phase and $\gamma^{\prime}$ phase, while the $<\frac{1}{2} 10>$ reflections can only be associated with $\gamma^{\prime \prime}$ phase [29]. As shown in Fig. 5a, b, the morphologies of $\gamma^{\prime \prime}$ phase and $\gamma^{\prime}$ phase in M718 alloy were similar with those in 718 alloy, showing dish shaped and spherical shaped, respectively. In addition,
Table 1 Chemical composition of the tested alloys (wt\%)

Table 2 Heat treatment preformed on the tested alloys

\begin{tabular}{lllllllllll}
\hline Alloy & $\mathrm{C}$ & $\mathrm{Ni}$ & $\mathrm{Cr}$ & $\mathrm{Al}$ & $\mathrm{Ti}$ & $\mathrm{Nb}$ & $\mathrm{Mo}$ & $\mathrm{P}$ & $\mathrm{B}$ & $\mathrm{Fe}$ \\
\hline M718 & 0.04 & 53.0 & 19.0 & 0.70 & 1.10 & 4.80 & 7.50 & 0.002 & 0.004 & Bal. \\
718 & 0.04 & 53.0 & 19.0 & 0.50 & 1.00 & 5.30 & 3.10 & 0.002 & 0.004 & Bal. \\
\hline
\end{tabular}

\begin{tabular}{lll}
\hline HT No. & Solution & Aging \\
\hline 1 & $960{ }^{\circ} \mathrm{C} \times 1 \mathrm{~h}$, AC & $720{ }^{\circ} \mathrm{C} \times 8 \mathrm{~h}$, cooled at $55^{\circ} \mathrm{C} / \mathrm{h}$ to $620^{\circ} \mathrm{C}, 620{ }^{\circ} \mathrm{C} \times 8 \mathrm{~h}$, AC \\
2 & $960{ }^{\circ} \mathrm{C} \times 1 \mathrm{~h}$, AC & $750{ }^{\circ} \mathrm{C} \times 8 \mathrm{~h}$, cooled at $55^{\circ} \mathrm{C} / \mathrm{h}$ to $620^{\circ} \mathrm{C}, 620^{\circ} \mathrm{C} \times 8 \mathrm{~h}$, AC \\
3 & $1020{ }^{\circ} \mathrm{C} \times 1 \mathrm{~h}$, AC & $750{ }^{\circ} \mathrm{C} \times 8 \mathrm{~h}$, cooled at $55^{\circ} \mathrm{C} / \mathrm{h}$ to $620^{\circ} \mathrm{C}, 620^{\circ} \mathrm{C} \times 8 \mathrm{~h}$, AC \\
4 & $1050{ }^{\circ} \mathrm{C} \times 1 \mathrm{~h}$, AC & $750{ }^{\circ} \mathrm{C} \times 8 \mathrm{~h}$, cooled at $55^{\circ} \mathrm{C} / \mathrm{h}$ to $620^{\circ} \mathrm{C}, 620{ }^{\circ} \mathrm{C} \times 8 \mathrm{~h}, \mathrm{AC}$ \\
\hline
\end{tabular}




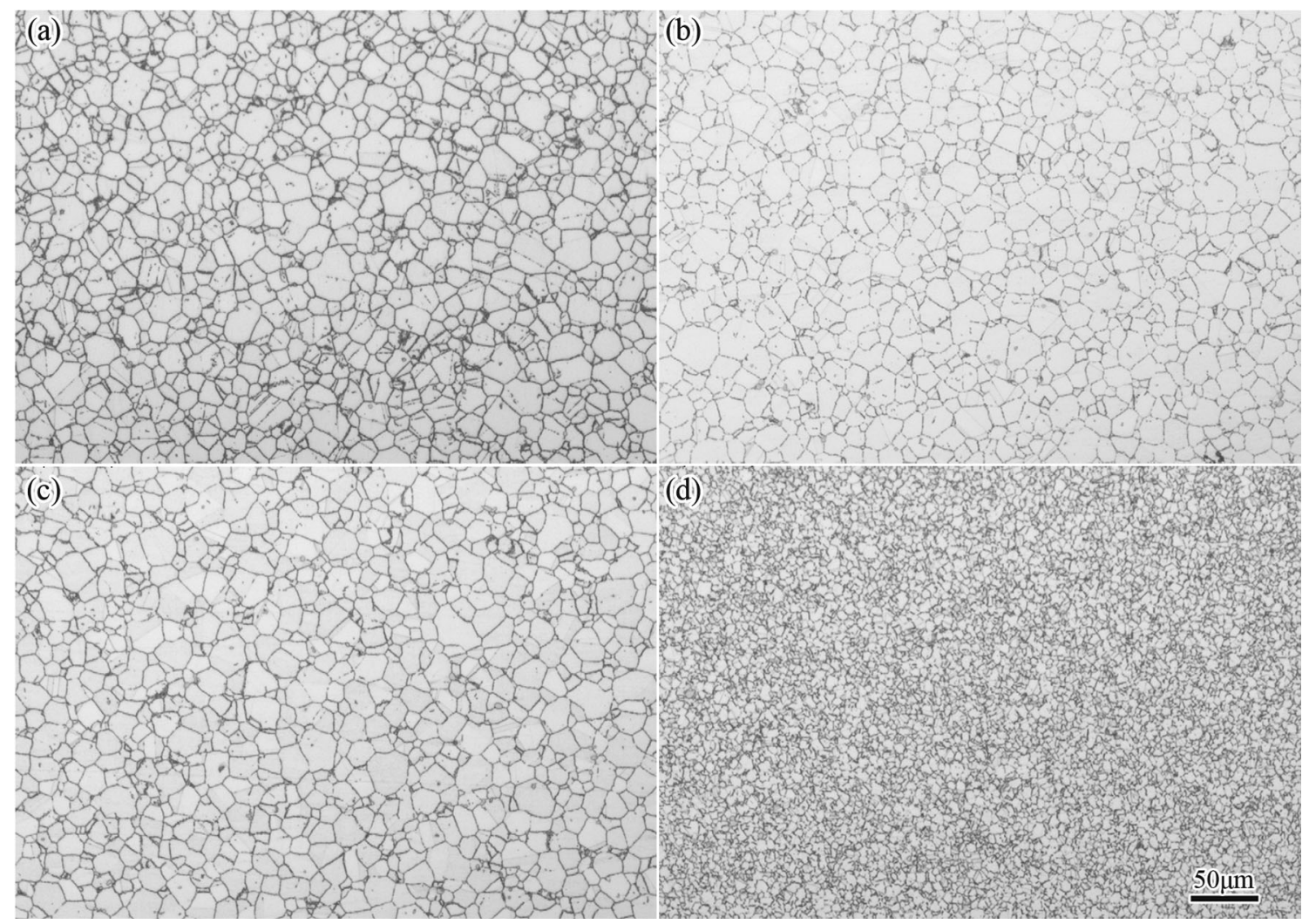

Fig. 1 OM micrographs of M718 alloy treated by a HT1, b HT3, c HT4, d 718 alloy treated by HT1

the typical combined morphology of $\gamma^{\prime \prime}$ phase and $\gamma^{\prime}$ phase was obtained. When the aging temperatures increased from 720 to $750{ }^{\circ} \mathrm{C}$ and from 620 to $650{ }^{\circ} \mathrm{C}$, the average diameter of $\gamma^{\prime \prime}$ phase increased from 11 to $20 \mathrm{~nm}$, and that of $\gamma^{\prime}$ phase increased from 10 to $18 \mathrm{~nm}$. After the standard heat treatment, the average diameters of $\gamma^{\prime \prime}$ phase and $\gamma^{\prime}$ phase were, respectively, 17 and $13 \mathrm{~nm}$ in 718 alloy. This result was consistent with the previous study [30] that the diameters of $\gamma^{\prime \prime}$ phase and $\gamma^{\prime}$ phase were $<20 \mathrm{~nm}$. Compared with that of 718 alloy, Mo decreased the size of $\gamma^{\prime \prime}$ phase after the standard heat treatment. Many researchers [31-33] studied the coarsening behavior of $\gamma^{\prime \prime}$ phase and showed that the coarsening kinetic of $\gamma^{\prime \prime}$ phase followed the time-law prediction of the LSW theory of $\mathrm{Nb}$ diffusioncontrolled growth. Mo decreased the diffusion rate of $\mathrm{Nb}$ in the matrix, and thus inhibited the growth of $\gamma^{\prime \prime}$ phase. It was found that larger $\gamma^{\prime \prime}$ phase was easier to transform into $\delta$ phase [34-37]. Therefore, Mo inhibited the transformation from $\gamma^{\prime \prime}$ phase to $\delta$ phase by decreasing the diffusion rate of $\mathrm{Nb}$.

\subsection{Tensile Properties}

The tensile properties of the tested alloys at room temperature and $680{ }^{\circ} \mathrm{C}$ are listed in Table 3 . When the solution temperature increased from 960 to $1020{ }^{\circ} \mathrm{C}$ and aging temperatures increased from 720 and 620 to 750 and $650{ }^{\circ} \mathrm{C}$ (from HT1 to HT3), both the strength and ductility of M718 alloy at room temperature and $680{ }^{\circ} \mathrm{C}$ increased noticeably. When the solution temperature increased to $1050{ }^{\circ} \mathrm{C}$ (HT4), the tensile strength was not improved further at room temperature, but began to decrease at $680{ }^{\circ} \mathrm{C}$. It should be noticed that the heat treatment HT3 was optimum for M718 alloy to obtain the best tensile properties both at room temperature and $680{ }^{\circ} \mathrm{C}$ in the present study. The yield strength of M718 alloy was lower than that of 718 alloy, while the ultimate strength and ductility were comparable with those of 718 alloy.

Figures 6 and 7 show the fractographs of the tested alloys tensiled at room temperature and $680{ }^{\circ} \mathrm{C}$. The fracture surfaces of M718 alloy showed the typical intergranular fracture both at room temperature and $680{ }^{\circ} \mathrm{C}$, as shown in Figs. 6, 7a, and the secondary intergranular cracks were observed on the fracture surfaces. Comparatively, the fracture surface of 718 alloy showed the typical transgranular fracture at room temperature as shown in Fig. $6 \mathrm{~b}$; however, at $680^{\circ} \mathrm{C}$, it showed the typical transgranular fracture in most areas and very small intergranular fracture zone located at the edge of the fracture surfaces, as shown in Fig. 7b, c. 


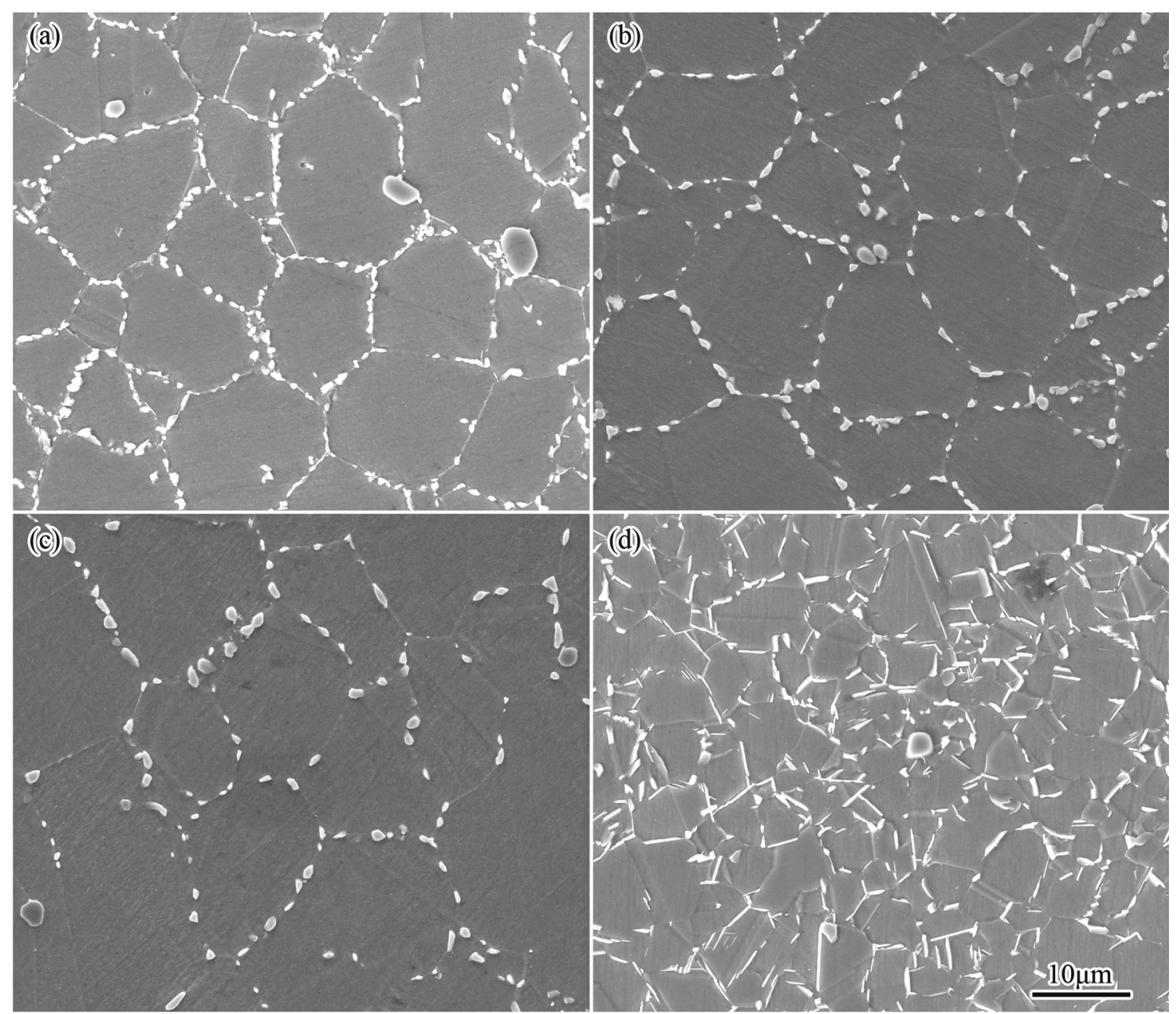

Fig. 2 SEM micrographs of M718 alloy treated by HT1 a, HT3 b, HT4 c, 718 alloy treated by HT1 d

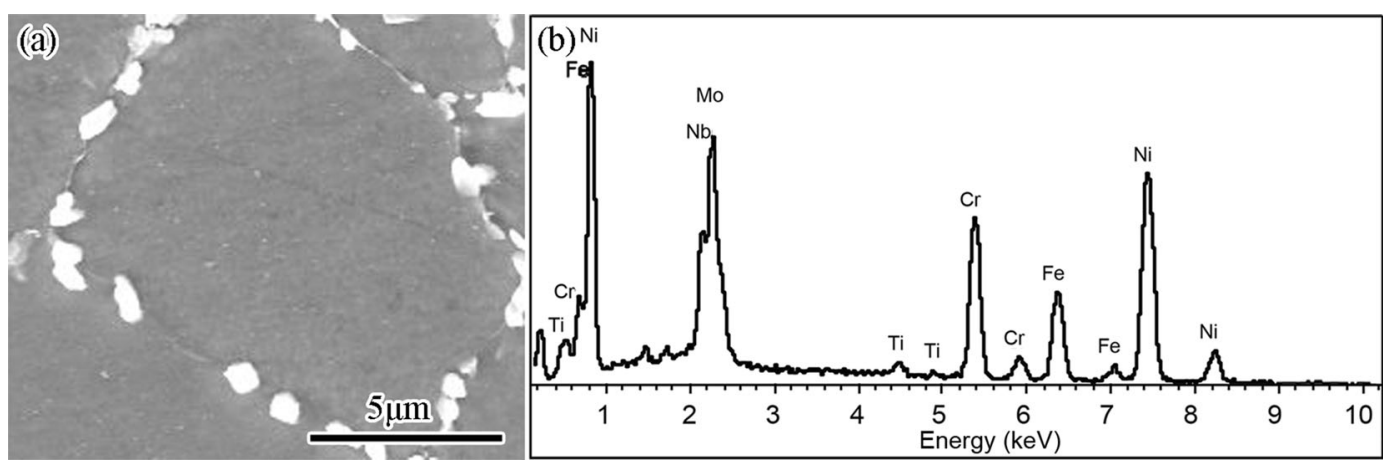

Fig. 3 SEM micrograph of the grain boundary precipitates a and corresponding EDS spectrum $\mathbf{b}$ of M718 alloy

\subsection{Stress Rupture Properties}

As listed in Table 4, the stress rupture lives at $680{ }^{\circ} \mathrm{C}$ and $725 \mathrm{MPa}$ of M718 alloy treated by different heat treatments were all about $23 \mathrm{~h}$. However, the life of 718 alloy was only $4.6 \mathrm{~h}$, which was about one-fourth of M718 alloy. The stress rupture ductility of M718 alloy treated by heat treatment HT1, HT2 and HT3 was all about 20\%, which was similar to that of 718 alloy. Treated by HT4, the stress rupture ductility of M718 alloy was reduced to $11 \%$.

The fractographs of the tested alloys ruptured at $680{ }^{\circ} \mathrm{C}$ and $725 \mathrm{MPa}$ are shown in Fig. 8. The fracture surfaces of M718 alloy treated by different heat treatments showed the same typical intergranular characteristic, as shown in 

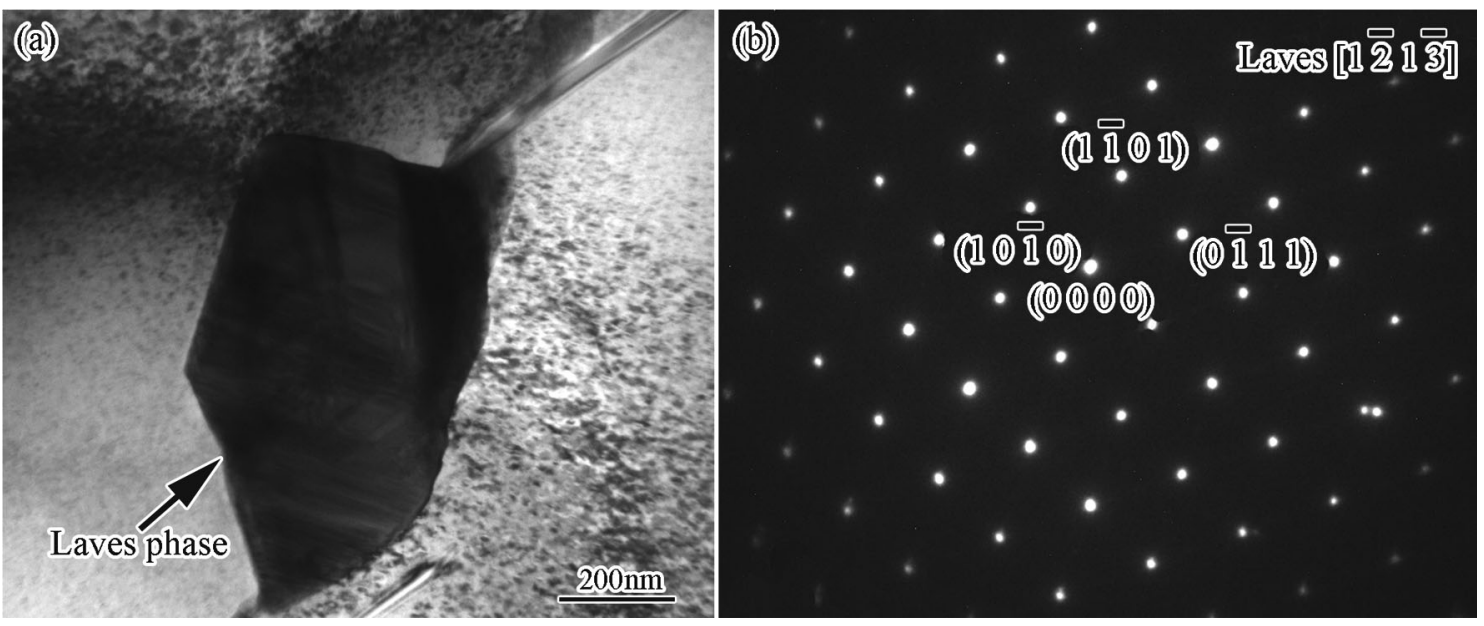

Fig. 4 Morphology of Laves phase on the grain boundaries in M718 alloy a and corresponding SAED pattern b
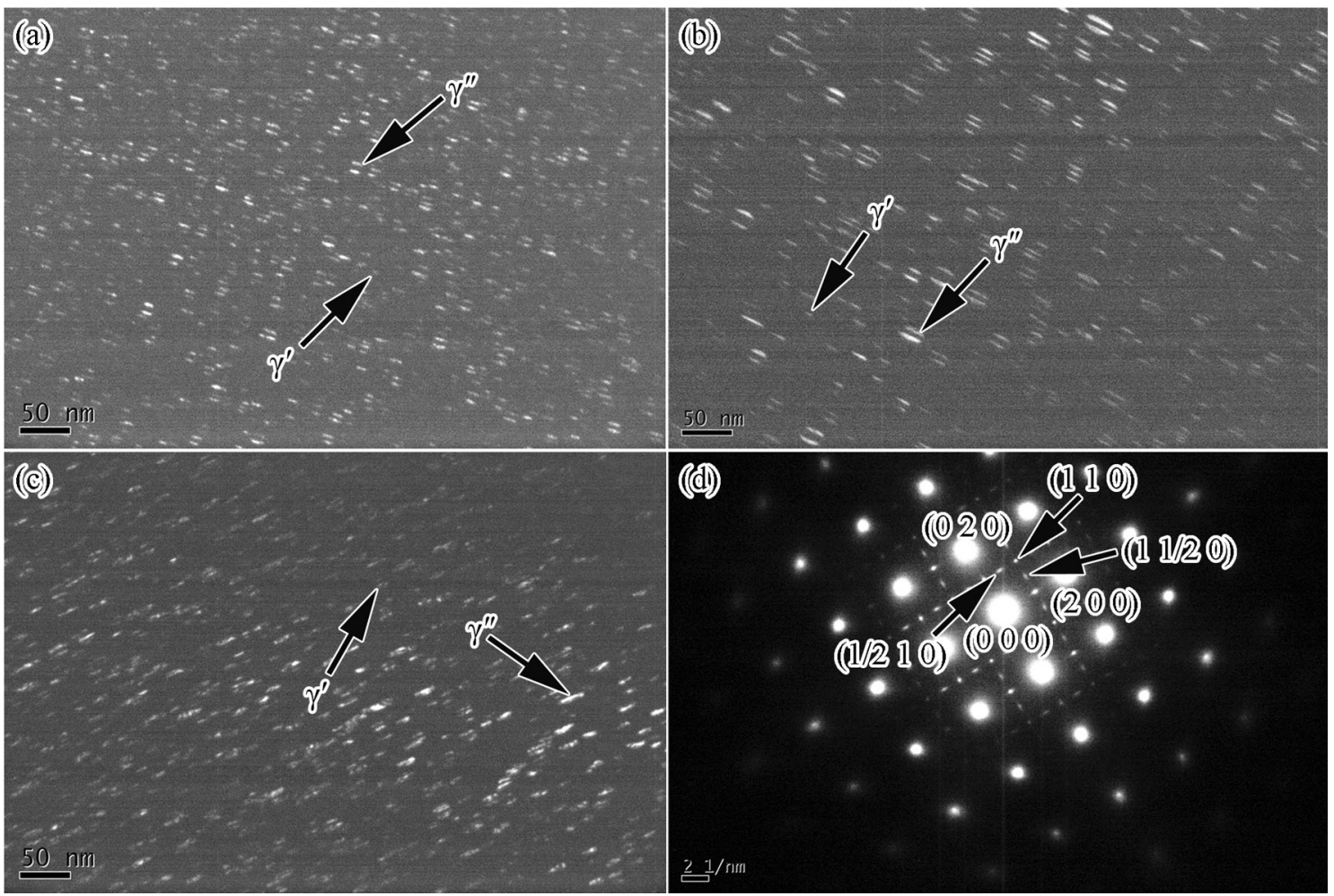

Fig. 5 TEM images of $\gamma^{\prime \prime}$ phase and $\gamma^{\prime}$ phase of M718 alloy treated by HT1 a, HT3 b, 718 alloy treated by HT1 c, d SAED pattern taken from the [001] matrix zone axis of M718 alloy

Fig. 8a. And the plastic deformation was observed clearly on the exposed grain boundaries. However, as shown in Fig. 8b, c, the fracture surface of 718 alloy was composed of the transgranular zone and intergranular zone. A large number of dimples were observed clearly in the transgranular zone, and some $M C$ carbides were located at the bottom of dimples. Nevertheless, the area of the intergranular zone was very small, and the intergranular zone was located at the outside part of the fracture surface.
Figure 9 shows the microstructures at the longitudinal section of the samples ruptured at $680{ }^{\circ} \mathrm{C}$ and $725 \mathrm{MPa}$. As presented in Fig. 9a, b, the cracks were observed to be initiated at the surfaces of all specimens and propagated along the grain boundaries toward inside. The microvoids were formed at the grain boundaries located at the inner part of both M718 alloy and 718 alloy samples, as shown in Fig. 9c, d. Comparatively, the amount of microvoids in M718 alloy was less than that 
Table 3 Tensile properties of the tested alloys at room temperature and $680{ }^{\circ} \mathrm{C}$

\begin{tabular}{|c|c|c|c|c|c|c|c|c|c|}
\hline \multirow[t]{2}{*}{ Alloy } & \multirow{2}{*}{$\begin{array}{l}\text { Heat } \\
\text { No. }\end{array}$} & \multicolumn{4}{|c|}{ Room temperature } & \multicolumn{4}{|l|}{$680{ }^{\circ} \mathrm{C}$} \\
\hline & & UTS (MPa) & YS (MPa) & $\mathrm{EL}(\%)$ & RA (\%) & UTS (MPa) & YS (MPa) & $\mathrm{EL}(\%)$ & RA $(\%)$ \\
\hline \multirow[t]{4}{*}{ M718 alloy } & HT1 & 1342 & 1005 & 17.0 & 15.9 & 1102 & 836 & 28.0 & 24.0 \\
\hline & HT2 & 1378 & 1081 & 19.3 & 19.1 & 1149 & 890 & 18.3 & 21.2 \\
\hline & HT3 & 1413 & 1121 & 20.7 & 30.1 & 1178 & 922 & 25.3 & 16.6 \\
\hline & HT4 & 1414 & 1120 & 26.0 & 35.0 & 1130 & 895 & 14.0 & 23.0 \\
\hline 718 alloy & HT1 & 1479 & 1201 & 25.3 & 43.4 & 1121 & 975 & 19.4 & 16.1 \\
\hline
\end{tabular}

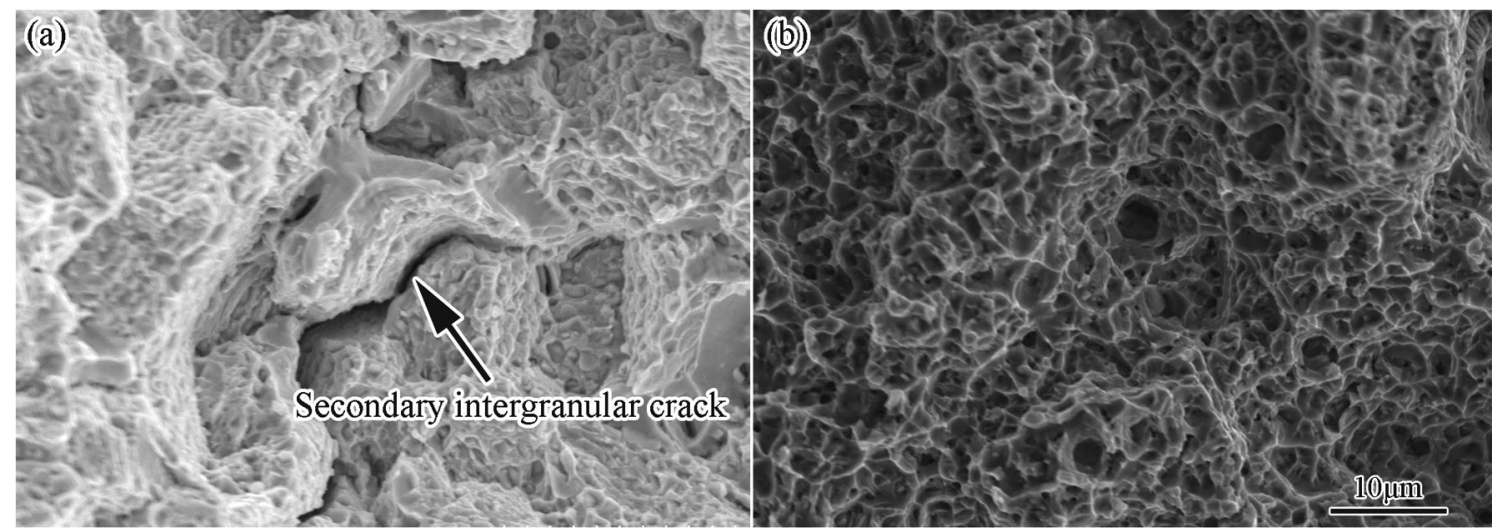

Fig. 6 Fractographs of the tensile ruptured specimens at room temperature: a M718 alloy treated by HT3, b 718 alloy treated by HT1

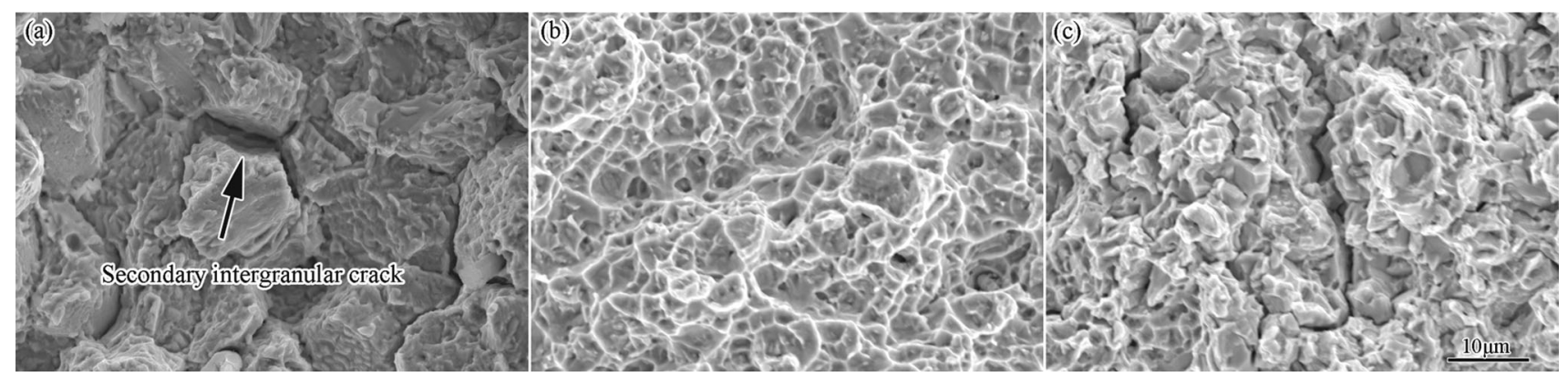

Fig. 7 Fractographs of the tensile ruptured specimens at $680{ }^{\circ} \mathrm{C}$ of M718 alloy treated by HT3 a, 718 alloy treated by HT1 b, c

Table 4 Stress rupture properties of the tested alloys at $680{ }^{\circ} \mathrm{C}$ and $725 \mathrm{MPa}$

\begin{tabular}{llll}
\hline Alloy & HT & Life (h) & Elongation (\%) \\
& No. & & \\
\hline M718 alloy & HT1 & 22.6 & 16.8 \\
& HT2 & 22.8 & 22.3 \\
& HT3 & 22.6 & 21.0 \\
718 alloy & HT4 & 23.1 & 11.4 \\
\hline
\end{tabular}

of 718 alloy, while the size of the microvoids in M718 alloy was larger than that of 718 alloy.

\section{Discussion}

For M718 alloy, Laves particles precipitated during the solution treatment at temperature ranging from 960 to $1050{ }^{\circ} \mathrm{C}$ in the present study. And the number of the intergranular precipitation of Laves phase decreased with increasing solution temperature. However, the solution temperature made no difference on the grain size of M718 alloy. It was implied that Laves phase precipitated during the heating up stage of the solution treatment process and hence inhibited the grain growth. The $\gamma^{\prime \prime}$ phase and $\gamma^{\prime}$ phase precipitated during the two-stage aging in temperature ranges of $\left(720-750^{\circ} \mathrm{C}\right)$ and $\left(620-650^{\circ} \mathrm{C}\right)$, and the sizes of 


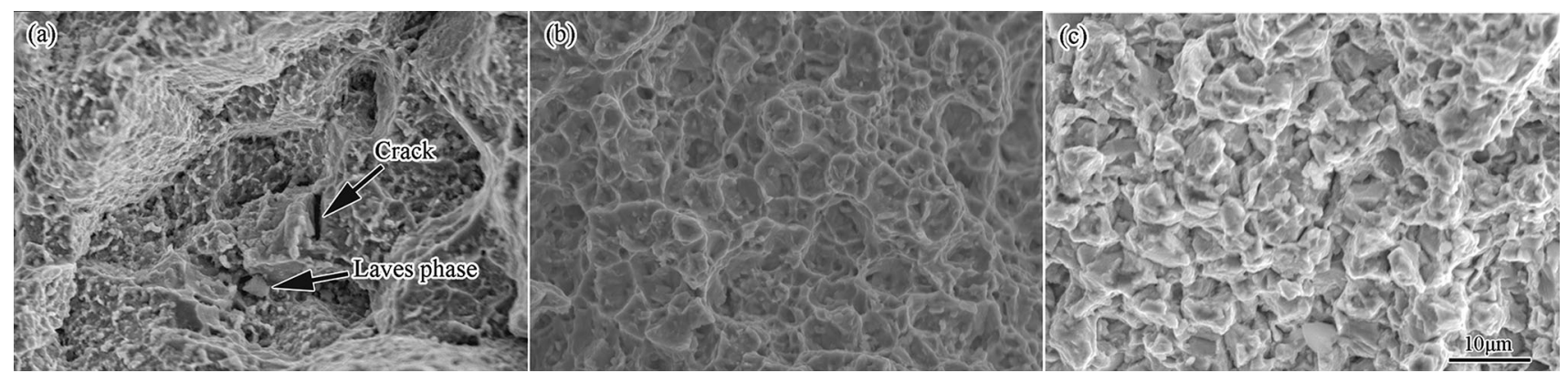

Fig. 8 Fractographs of the tested alloys stress ruptured at $680{ }^{\circ} \mathrm{C}$ and $725 \mathrm{MPa}$ a M718 alloy treated by HT2, b, c 718 alloy treated by HT1
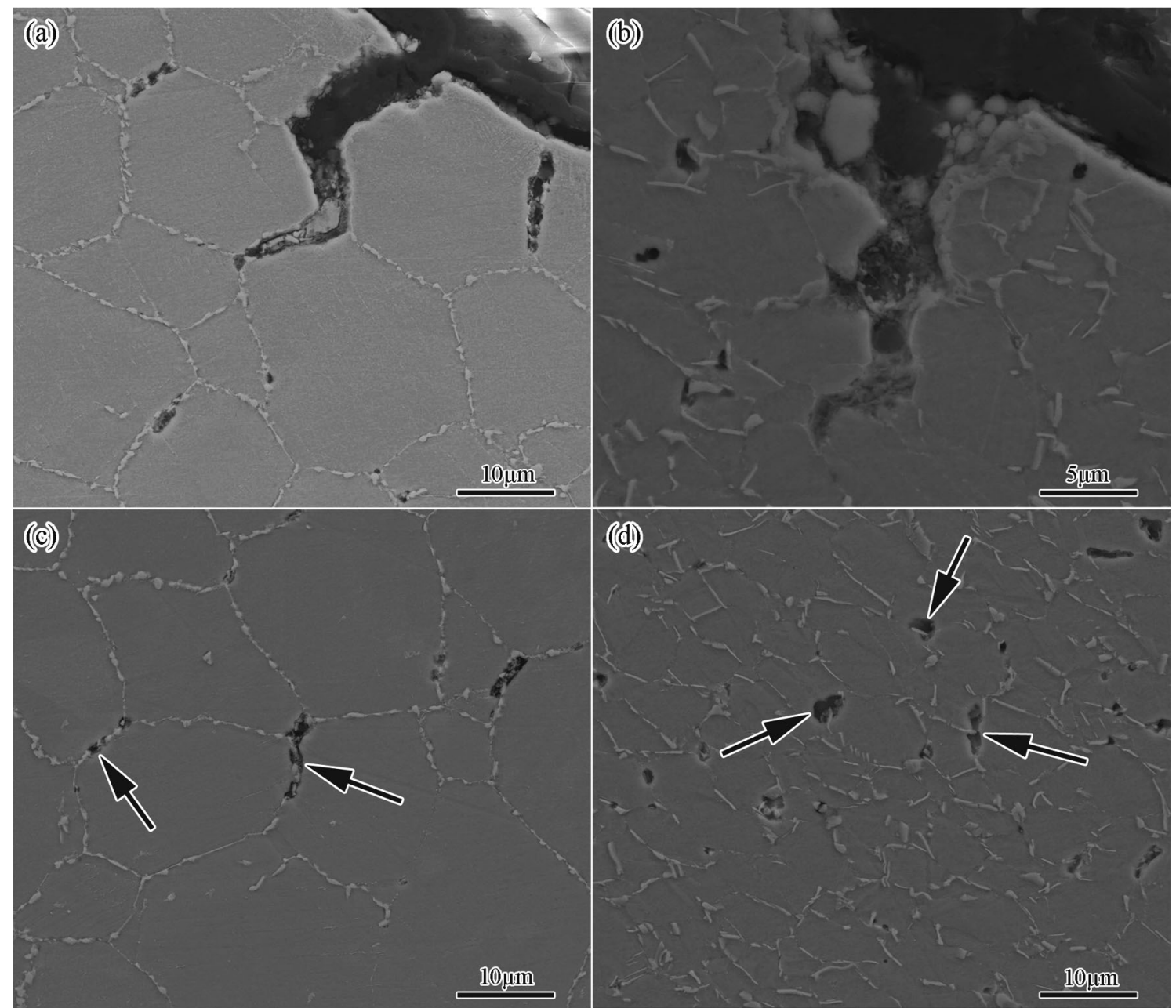

Fig. 9 Microstructures of cross section of the tested alloys ruptured at $680{ }^{\circ} \mathrm{C}$ and $725 \mathrm{MPa}$ : a, c M718 alloy treated by $\mathrm{HT} 1$, b, d 718 alloy treated by HT1

$\gamma^{\prime \prime}$ phase and $\gamma^{\prime}$ phase in M718 alloy noticeably increased with rising the aging temperatures as shown in Fig. 5.

The mechanical properties of M718 alloy were directly influenced by the microstructure or heat treatments. For HT1 and HT2, at the same solution temperature of $960{ }^{\circ} \mathrm{C}$, increasing the aging temperatures from 720 to 750 and 620 to $650{ }^{\circ} \mathrm{C}$, there was no difference on the intergranular precipitation behavior of Laves phase, while the sizes of $\gamma^{\prime \prime}$ phase and $\gamma^{\prime}$ phase increased. As a result, the yield and ultimate tensile strengths of M718 alloy treated by HT2 were higher than those of M718 alloy treated by HT1. This seems to be consistent with the results $[38,39]$ that the increment of the size of strengthening phases increases the strength of the alloy since the coherency strain was the 
main strengthening mechanism when the volume fraction of strengthening phases was lower than $20 \%$. However, this could only explain that the yield strength of M718 alloy increased with increasing sizes of $\gamma^{\prime \prime}$ phase and $\gamma^{\prime}$ phase, but fail to explain the variation of ultimate strength with the heat treatments. Because M718 alloy treated by different heat treatments all exhibited the typical intergranular fracture, which means that the ultimate tensile strength was determined by the grain boundary strength. Apparently, the intergranular precipitation of Laves phase in M718 alloy treated by HT3 is optimum, which gave the alloy the highest ultimate strength. Although the higher solution temperature reduced the precipitation of Laves phase, too small amount of Laves phase might largely reduce the grain boundary strength. As a result, compared with that of HT3, both the ultimate strength and yield strength at $680{ }^{\circ} \mathrm{C}$ were reduced in the case of HT4 with the solution temperature of $1050{ }^{\circ} \mathrm{C}$.

718 alloy is hardened mainly by the precipitation of $\gamma^{\prime \prime}$ phase [1-3]. A higher $\mathrm{Nb}$ content can improve the strength of 718 alloy remarkably [40]. The content of $\mathrm{Nb}$ in M718 alloy was obviously lower than 718 alloy, so more $\gamma^{\prime \prime}$ phases were expected to precipitate in 718 alloy. The grain size of M718 alloy was much bigger than that of 718 alloy. According to the Hall-Petch relationship, the strength of the alloy increases as the grain size decreases when the grain size is in the range of $0.3-400 \mu \mathrm{m}$ [41]. Due to the above reasons, the tensile strength of M718 alloy was a little lower than that of 718 alloy.

Although both Laves phase and $\delta$ phase can refine the grain size of the alloy, the extra high addition of Mo would inhibit the recrystallization and hence increased the grain size of M718 alloy. As a result, the grain size of M718 alloy was larger than that of 718 alloy under the same rolling condition.

The stress rupture lives of M718 alloy were hardly influenced by heat treatments performed in this study. Under all of heat treatment conditions, the fracture surfaces of M718 alloy exhibited the typical intergranular fracture, so the rupture lives were determined by the initiation and propagation of the cracks at grain boundaries. It was observed that the cracks were all initiated at and propagated along the interface between Laves phase and the matrix. Thus, the lives of M718 alloy treated by different heat treatments were not different from each other.

The fracture surface of 718 alloy specimen ruptured at $680{ }^{\circ} \mathrm{C}$ and $725 \mathrm{MPa}$ also exhibited the typical intergranular fracture. The microvoids formed in 718 alloy were much more than those in M718 alloy. The large amount of microvoids would largely reduce the effective area of the cross section, and finally the specimen was pulled to rupture, leaving the transgranular fracture area. Apparently, the initiation of the cracks was very fast, so the life of 718 alloy was only $4.6 \mathrm{~h}$.

The strengths of 718 alloy at room temperature and $680{ }^{\circ} \mathrm{C}$ were higher than those of $\mathrm{M} 718$ alloy, and the fracture surfaces of the specimens of 718 alloy exhibited the typical transgranular fracture, so the grain boundary cohesion was not the main reason for the shorter life. Compared with M718 alloy, the Mo content is very lower in 718 alloy. It is reasonable to assume that the initiation and propagation of the cracks might be influenced mainly by the diffusion rate of the elements. The addition of Mo as high as $7.50 \mathrm{wt} \%$ largely reduced the diffusion rate when the alloy stressed at $680{ }^{\circ} \mathrm{C}$ and $725 \mathrm{MPa}$, and hence prolonged the rupture life of the alloy noticeably. In addition, the finer grain size also favored the initiation of the intergranular cracks during the stress rupture test, and hence, the conclusion could not be drawn directly that the life of M718 alloy was much longer than that of 718 alloy. However, the life was only $45 \mathrm{~h}$ for 718 alloy ruptured at $650{ }^{\circ} \mathrm{C}$ and $690 \mathrm{MPa}$, and $53 \mathrm{~h}$ for 718 alloy ruptured at $680{ }^{\circ} \mathrm{C}$ and $540 \mathrm{MPa}$ [42]. It is reasonable to believe that the addition of Mo has a noticeable effect on the stress rupture life of 718 alloy.

The fracture surfaces of the tensile and stress rupture specimens of M718 alloy showed the intergranular fracture characteristic in this study. It indicated that the grain boundary strength of M718 alloy was always lower than the intragranular strength. However, the fracture surfaces of the specimens of 718 alloy were transgranular fracture at room temperature and mixed fracture at high temperature, which were consistent with the previous study [43]. It was shown that the grain boundary strength of 718 alloy was higher than the intragranular strength at room temperature. As the temperature increased, the grain boundary strength decreased quickly. When the grain boundary strength was lower than the intragranular strength, the fracture surface of 718 alloy specimen was mixed mode.

\section{Conclusions}

1. Laves phase precipitates at the grain boundaries of M718 alloy instead of $\delta-\mathrm{Ni}_{3} \mathrm{Nb}$ phase in 718 alloy, and $\gamma^{\prime \prime}$ phase and $\gamma^{\prime}$ phase precipitate in the matrix of M718 alloy as that of 718 alloy.

2. Increasing the solution temperature from 960 to $1050{ }^{\circ} \mathrm{C}$ noticeably reduces the intergranular precipitation of Laves phase, and rising the two-stage aging temperatures markedly increases the sizes of $\gamma^{\prime \prime}$ phase and $\gamma^{\prime}$ phase.

3. The strength of M718 alloy increases by increasement of the sizes of $\gamma^{\prime \prime}$ phase and $\gamma^{\prime}$ phase and appropriate precipitation of Laves phase at the grain boundaries. 
The stress rupture life of M718 alloy is not influenced by heat treatments, because the cracks are initiated and propagated at the Laves/matrix interface along the grain boundaries.

\section{References}

[1] A. Cruzado, B. Gan, M. Jiménez, D. Barba, K. Ostolaza, A. Linaza, J.M. Molina-Aldareguia, J. Llorca, J. Segurado, Acta Mater. 98, 242 (2015)

[2] D. Zhang, W. Niu, X. Cao, Z. Liu, Mater. Sci. Eng. A 644, 32 (2015)

[3] M. Fisk, J. Andersson, R.D. Rietz, S. Haas, S. Hall, Mater. Sci. Eng. A 612(33), 202 (2014)

[4] H. Qin, Z. Bi, H. Yu, G. Feng, J. Du, J. Zhang, J. Alloys Compd. 740, 997 (2018)

[5] L. Cheng, X. Xue, B. Tang, D. Liu, J. Li, H. Kou, J. Li, Mater. Sci. Eng. A 606, 24 (2014)

[6] J. Du, X. Lv, Q. Deng, Y. Luo, Rare Metal Mater. Eng. 46, 2359 (2017)

[7] M. Anderson, A.L. Thielin, F. Bridier, P. Bocher, J. Savoie. Mater. Sci. Eng. A 679, 48 (2017)

[8] Z.S. Yu, J.X. Zhang, Y. Yuan, R.C. Zhou, H.J. Zhang, H.Z. Wang, Mater. Sci. Eng. A 634, 55 (2015)

[9] S. Fu, J. Dong, M. Zhang, N. Wang, X. Xie, Superalloy 718 and Derivatives (Wiley, New York, 2010), p. 281

[10] W.R. Sun, S.R. Guo, D.Z. Lu, Z.Q. Hu, Metall. Mater. Trans. 28, 649 (1997)

[11] Y. Jiang, X. Xiao, X. Qin, J. Shenyang Ligong Univ. 6, 10 (2016)

[12] S.G. Tian, X. Wang, C. Liu, W.R. Sun, Mater. Sci. Forum 748, $672(2013)$

[13] S. Guan, C. Cui, Y. Yuan, Y. Gu, Mater. Sci. Eng. A 662, 275 (2016)

[14] K. Takasawa, H. Chinen, T. Ohkawa, E. Maeda, T. Hatano, ISIJ Int. 55, 1100 (2015)

[15] V. Biss, D.L. Sponseller, Metall. Trans. 4, 1953 (1973)

[16] Z. Zhu, H. Basoalto, N. Warnken, R.C. Reed, Acta Mater. 60, 4888 (2012)

[17] P.P. Hu, J.Y. Chen, Q. Feng, Y.H. Chen, L.M. Cao, X.H. Li, Chin. J. Nonferrous Met. 33, 144 (2011)

[18] J. Zhang, J. Li, T. Jin, X. Sun, Z. Hu, Mater. Sci. Eng. A 527, $3051(2010)$
[19] X.G. Liu, L. Wang, L.H. Lou, J. Zhang, J. Mater. Sci. Technol. 31, 143 (2015)

[20] Y. Liang, S. Li, C. Ai, Y. Han, S. Gong, Prog. Nat. Sci. Mater. Int. 26, 112 (2016)

[21] J.P. Collier, S.H. Wong, J.K. Tien, J.C. Phillips, Metall. Tran. A 19, 1657 (1988)

[22] M.K. Miller, Micron 32, 757 (2001)

[23] L. Letellier, M. Guttmann, D. Blavette, Philos. Mag. Lett. 70, 189 (1994)

[24] L. Letellier, A. Bostel, D. Blavette, Scripta Metall. Mater. 30, 1503 (1994)

[25] E. Cadel, D. Lemarchand, S. Chambreland, D. Blavette, Acta Mater. 50, 957 (2002)

[26] D. Blavette, P. Duval, L. Letellier, M. Guttmann, Acta Mater. 44, 4995 (1996)

[27] W.J. Hui, H. Dong, Y.P. Weng, J. Shi, X.Z. Zhang, Acta Metall. Sin. (Engl. Lett.) 40, 1274 (2004)

[28] J.X. Dong, X.B. Liu, X.S. Xie, R.G. Thompson, Acta Metall. Sin. (Engl. Lett.) 6, 510 (1997)

[29] R.C. Reed, The Superalloys (Cambridge University Press, Cambridge, 2006), p. 15

[30] H. Lifeng, S. Wenru, G. Shouren, H. Zhuangqi, Rare Met. Mater. Eng. 37, 1193 (2008)

[31] Y.F. Han, P. Deb, M.C. Chaturvedi, Met. Sci. 16, 555 (1982)

[32] S.E. Axter, D.H. Polonis, Mater. Sci. Eng. 36, 71 (1978)

[33] J.X. Dong, X.S. Xie, S.H. Zhang, J. Univ. Sci. Technol. B 17, 134 (1995)

[34] S. Tian, X. Wang, J. Xie, C. Liu, Z. Guo, J. Liu, W. Sun, Acta Metall. Sin. (Engl. Lett.) 49, 845 (2013)

[35] R. Cozar, A. Pineau, Metall. Trans. 4, 47 (1973)

[36] M. Sundararaman, P. Mukhopadhyay, S. Banerjee, Metall. Trans. 19, 453 (1988)

[37] J.X. Dong, X.S. Xie, Z.C. Xu, S.H. Zhang, M.Z. Chen, J.F. Radavich, Miner. Met. Mater. Soc. 2, 649 (1994)

[38] J.T. Guo, Materials Science and Engineering for Superalloys (Science Press, Beijng, 2008), p. 505

[39] D.F. Paulonis, J.M. Oblak, D.S. Duvall, ASM Trans. Quart. 62, 611 (1969)

[40] X.S. Xie, J.X. Dong, M.C. Zhang, S.H. Fu, Mater. Sci. Forum 546-549, 1281 (2007)

[41] Y.N. Yu, Fundamentals of Materials Science (Higher Education Press, Beijing, 2006), p. 506

[42] Chinese Handbook of Aeronautical Materials Committee, Chinese Handbook of Aeronautical Materials (China Standards Press, Beijing, 2002), p. 536

[43] R.Y. Liu, Dissertation, University of Dong Hua, 2013. (in Chinese) 